\title{
Women's healthcare decision-making capacity and HIV testing in sub-Saharan Africa: a multi-country analysis of demographic and health surveys
}

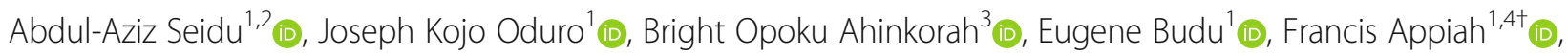
Linus Baatiema ${ }^{1+}$ (D), Edward Kwabena Ameyaw ${ }^{3+}$ (D) and Francis Sambah ${ }^{5^{*+}}$ (D)

\begin{abstract}
Background: Global commitment to stop Human Immunodeficiency Virus (HIV) and ensure access to HIV treatment calls for women empowerment, as these efforts play major roles in mother-to-child transmission. We examined the association between women's healthcare decision-making capacity and uptake of HIV testing in subSaharan Africa.

Methods: We used data from the current Demographic and Health Surveys (DHS) of 28 countries in sub-Saharan Africa, conducted between January 1, 2010 and December 31, 2018. At the descriptive level, we calculated the prevalence of HIV testing in each of the countries. This was followed by the distribution of HIV testing across the socio-demographic characteristics of women. Finally, we used binary logistic regression assess the likelihood of HIV testing uptake by women's health care decision-making capacity and socio-demographic characteristics. The results were presented as Crude Odds Ratios (COR) and Adjusted Odds Ratios (AOR) with their corresponding 95\% confidence intervals signifying precision. Statistical significance was set at $p$-value $<0.05$.

Results: We found that prevalence of HIV testing uptake in the 28 sub-Saharan African countries was 64.4\%, with Congo DR having the least $(20.2 \%)$ and the highest occurred in Rwanda (97.4\%). Women who took healthcare decisions alone $[\mathrm{COR}=3.183, \mathrm{Cl}=2.880-3.519]$ or with their partners $[\mathrm{COR}=2.577, \mathrm{Cl}=2.335-2.844]$ were more likely to test for HIV, compared to those whose healthcare decisions were taken by others, and this persisted after controlling for significant covariates: $[A O R=1.507, C l=1.321-1.720]$ and $[A O R=1.518, C l=1.334-1.728]$ respectively.

Conclusion: Sub-Saharan African countries intending to improve HIV testing need to incorporate women's healthcare decision-making capacity strategies. These strategies can include education and counselling. This is essential because our study indicates that the capacity of women to make healthcare decisions has an association with decision to test for their HIV status.
\end{abstract}

Keywords: Healthcare decision-making capacity, HIV, Sub-Saharan Africa, Testing, Women

\footnotetext{
* Correspondence: francis.sambah@stu.ucc.edu.gh

${ }^{\dagger}$ Francis Appiah, Linus Baatiema, Edward Kwabena Ameyaw and Francis Sambah contributed equally to this work.

${ }^{5}$ Department of Health, Physical Education, and Recreation, University of Cape Coast, Cape Coast, Ghana

Full list of author information is available at the end of the article
}

(c) The Author(s). 2020 Open Access This article is licensed under a Creative Commons Attribution 4.0 International License, which permits use, sharing, adaptation, distribution and reproduction in any medium or format, as long as you give appropriate credit to the original author(s) and the source, provide a link to the Creative Commons licence, and indicate if changes were made. The images or other third party material in this article are included in the article's Creative Commons licence, unless indicated otherwise in a credit line to the material. If material is not included in the article's Creative Commons licence and your intended use is not permitted by statutory regulation or exceeds the permitted use, you will need to obtain permission directly from the copyright holder. To view a copy of this licence, visit http://creativecommons.org/licenses/by/4.0/ The Creative Commons Public Domain Dedication waiver (http://creativecommons.org/publicdomain/zero/1.0/) applies to the data made available in this article, unless otherwise stated in a credit line to the data. 


\section{Background}

Human Immunodeficiency Virus (HIV) and Acquired Immune Deficiency Syndrome (AIDS) constitute one of the world's most serious public health problems [1]. Worldwide, an estimated 1.8 million newly infected HIV cases were recorded in 2017 [1]. This was made up of 180,000 children predominantly living in sub-Saharan Africa (SSA), who were infected by their HIV-positive mothers during pregnancy, childbirth, or breastfeeding [2]. HIV testing, especially among women aged $15-49$, is a challenge in SSA [3, 4]. Some of the challenges identified in previous studies include but not limited to HIV-related stigma from health professionals, HIV status disclosure dilemma, unintended pregnancy, intimate partner violence, HIV and environmental structural barriers, distress, and fear related to maternal and child health $[3,5]$. The few studies on this subject target women who access health services in specific countries [6].

Global commitment to stopping new HIV infections and ensuring access to treatment calls for women empowerment, due to the major role it plays in mother-tochild-transmission [1, 7]. Women's decision-making capacity is imperative for ensuring HIV testing and addressing the pandemic [8], especially in SSA. The importance of women's decision-making capacity in the area of HIV testing has been highlighted to build women's confidence to prevent HIV infection, especially mother to child infection [9]. Women's access to HIV testing depends substantially on the level to which they have been empowered to make decisions [10]. It is believed that a woman who is empowered culturally, politically, or professionally has the confidence to decide on HIV testing, as she does not depend on her husband or partner to make decision to test for HIV or not [11].

The Theory of Gender and Power (TGP) by Connell [12] could guide the exploration of association between women's healthcare decision-making capacity and HIV testing. The TGP postulates that power dynamics between men and women are manifested in three major structures: sexual division of labour, sexual division of power, structure of social exposure and affective attachment $[12,13]$. These structures provide a description of the gendered relationships between men and women which explain the power and role dynamics drifting more dominance to the males making the females subservient. Hence, a woman's decision to go for testing may depend on whether there is equality between her and the partner, societal expectations, and norms in relation to who should decide on going for testing and whether or not there is male dominance in the home. According to the theory, although there is a distinction between these structures, they overlap and thus may not be considered in isolation from one other. These structures are also maintained through societal and institutional social mechanisms $[13,14]$. These societal and institutional social mechanisms include specific socio-demographic characteristics of individuals.

For women, the specific socio-demographic characteristics which, together with healthcare decision making capacity, influence HIV testing include age, education, wealth, employment, residence, and parity $[8,15]$. In SSA, literature on women's decision-making capacity and HIV testing is limited to specific countries such as Tanzania [8], Ethiopia [16], and South Africa [17] and mostly among women who are accessing healthcare services at health facilities $[18,19]$. This suggests the paucity of studies on women's decision-making and HIV testing in SSA. It is, therefore, imperative to conduct a study in a broader context covering the entire SSA in order to empower and imbue women with a positive attitude for HIV testing. In light of the foregoing, we examined women's healthcare decision-making capacity and HIV testing in SSA. We hypothesized that women who have the capacity to take decisions on healthcare alone or with their partners are more likely to test for their HIV status. Findings from such a multi-country study will provide evidence on the need and how to strengthen existing strategies to improve HIV testing and counselling by tackling women's decision-making capacity.

\section{Methods}

We used pooled data from the current Demographic and Health Surveys (DHS) conducted from January 1, 2010 and December 31, 2018 in 28 countries in SSA (see Fig. 1). DHS is a nationwide survey collected every fiveyear period across low- and middle-income countries. DHS focuses on maternal and child health by interviewing women of reproductive age (15-49 years) and men between 15 and 64 years. DHS surveys followed the same standard procedures - sampling, questionnaire development, and data collection. However, data cleaning, coding, and analysis were done in this study for cross-country comparison. The survey employed a stratified two stage sampling technique. The initial stage involved the selection of points or clusters (enumeration areas [EAs]), followed by a systematic sampling of households listed in each cluster or EA. For this study, the women's file of the DHS data was used. All the participants were women in their reproductive age (15-49), who were usual members of the selected households and/or visitors who slept in the household on the night before the survey. In this study, only women in unions who had complete information on all the variables of interest were included $(N=195,307)$. We relied on the "Strengthening the Reporting of Observational Studies in Epidemiology" (STROBE) statement in writing the manuscript. 


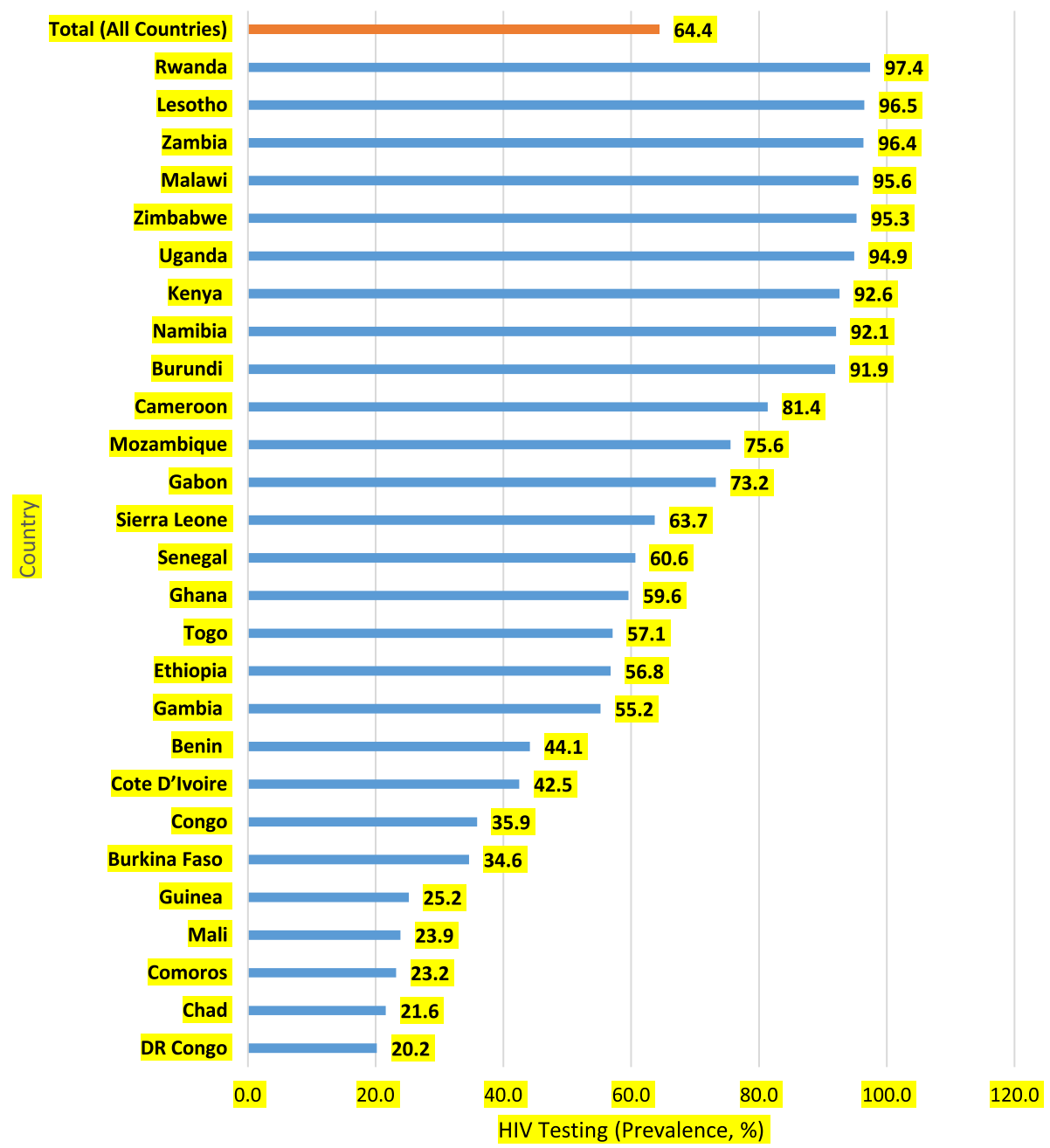

Fig. 1 Prevalence of HIV testing among women in SSA

\section{Definition of variables}

\section{Outcome variable}

The outcome variable was HIV testing uptake. It was derived from the question "have you ever tested for HIV?" and the responses were coded as " $1=$ Yes and $0=\mathrm{No}$ ".

\section{Explanatory variables}

Thirteen explanatory variables were considered in our study, including the key explanatory variable (women's decision-making on healthcare). Women's decision-making on healthcare was derived from the question "Who usually makes decisions about healthcare for yourself: you, your (husband/partner), you and your (husband/partner) jointly, or someone else?" The responses were categorised as respondent alone, respondent and husband/partner, husband/partner alone, someone else, and other. These were recoded into respondent $/$ woman alone $=1$, respondent and husband/partner $=2$, husband/partner alone $=3$ and other $=4$ (family members and friends).
Besides women's decision-making on healthcare, 12 additional variables were included in the study. These are survey country, age, educational level, marital status, religion, wealth status, place of residence, parity, occupation, and exposure to mass media (radio, television, and newspaper). Apart from survey country which was predetermined based on the geographical scope of the study, the selection of the rest of the variables was based on their association with HIV testing uptake in previous studies $[6-8,20-25]$. Marriage was recoded into 'married (1)' and 'cohabiting (2)'. Occupation was captured as 'not working (0)', 'managerial (1)', 'clerical (2)', 'sales (3)', 'agricultural (4)', 'household/domestic (5)', 'services (6)', and 'manual (7)'. We recoded parity (birth order) as 'zero birth'(0), 'one birth (1)', 'two births (2)', 'three births (3)', and four or more births (4)'. Lastly, religion was recoded as 'Traditional religion (1)', 'Christianity (2)', 'Islam (3)', 'No religion (4)', and 'Other religion (5)' (e.g. Hinduism, Buddhism, Atheism, Juddaism, Taoism, Confucianism, Sikhism). 


\section{Statistical analyses}

The data was analysed with STATA version 14.2 for Mac OS. The analysis was done in three steps. The first step was the computation of the prevalence of HIV testing uptake in SSA (see Fig. 1). The second step was a cross-tabulation by which we calculated the prevalence and proportions of HIV testing across the socio-demographic characteristics (see Table 1). Then, we conducted a bivariate logistic regression (Model I) and multivariable regression (Model II) analyses to assess the predictors of HIV testing among women in SSA (see Table 2). All frequency distributions were weighted and the survey command (svy) in STATA was used to adjust for the complex sampling structure of the data in the regression analyses. There was multicollinearity between knowing a place for HIV testing and HIV testing uptake. Due to this, it was taken out of the analysis. After it was taken out, there was no evidence of multicollinearity among the remaining variables (Mean VIF $=1.35$, Maximum VIF $=1.70$, Minimum VIF $=1.05$ ). All results of the logistic regression analyses were presented as Crude Odds Ratios (CORs) and Adjusted Odds Ratios (AORs) at 95\% confidence intervals (CIs).

\section{Results}

Prevalence of HIV testing among women in sub-Saharan Africa

Figure 1 shows the prevalence of HIV testing in entirety and in each of the 28 SSA countries. Overall, the prevalence of HIV testing was $64.4 \%$. We found that the prevalence of HIV testing ranged from $20.2 \%$ in Congo DR to $97.4 \%$ in Rwanda.

\section{Socio-demographic characteristics and prevalence of HIV testing}

Table 1 summarises the prevalence of HIV testing across the included socio-demographic characteristics. The highest prevalence of HIV testing was among women with higher education (92.9\%) and the lowest prevalence was among those who were Traditionalists (32.8\%). All the socio-demographic characteristics showed statistically significant relationship with HIV testing (Table 1).

\section{Association between women's healthcare decision- making and socio-demographic characteristics on HIV testing in sub-Saharan Africa}

Table 2 shows results on the association between women's healthcare decision-making capacity and sociodemographic factors associated with HIV testing among women in SSA. The results indicate that women who took healthcare decisions alone $[\mathrm{COR}=3.183, \mathrm{CI}=2.880$ 3.519] or with their partners [COR $=2.577, \mathrm{CI}=2.335-$ 2.844] were more likely to test for HIV compared to those whose healthcare decisions were taken by others, and this persisted after controlling for significant covariates
$[\mathrm{AOR}=1.507, \mathrm{CI}=1.321-1.720]$ and $[\mathrm{AOR}=1.518, \mathrm{CI}=$ $1.334-1.728$ ], respectively (see Model II). With the covariates, women aged $20-24 \quad[\mathrm{AOR}=1.351-\mathrm{CI}=1.273-$ 1.433], richest women $[\mathrm{AOR}=2.561, \mathrm{CI}=2.418-2.713$, those with parity 4 or more $[\mathrm{AOR}=4.788-\mathrm{CI}=4.488$ 5.108] were more likely to test for HIV, compared to those aged 15-19, those in the poorest wealth quintile, and those with parity 0 , respectively. On the other hand, women aged 45-49 [AOR $=0.383, \mathrm{CI}=0.355-0.413]$, those with no formal education $[\mathrm{AOR}=0.259, \mathrm{CI}=0.227$ 0.294], married women $[\mathrm{AOR}=0.914, \mathrm{CI}=0.879-0.951$, those with no religion $[\mathrm{AOR}=0.771, \mathrm{CI}=0.682-0.873]$, those who were not working $[\mathrm{AOR}=0.589, \mathrm{CI}=0.471-$ 0.737], those in agriculture $[\mathrm{AOR}=0.571, \mathrm{CI}=0.456-$ $0.716]$, those in rural areas $[\mathrm{AOR}=0.732, \mathrm{CI}=0.707$ 0.759 ], those not exposed to newspaper $[\mathrm{AOR}=0.656 \mathrm{CI}=$ $0.510-0.843]$, those not exposed to radio $[\mathrm{AOR}=0.757$, $\mathrm{CI}=0.693-0.828]$, those not exposed to television $[\mathrm{AOR}=$ $0.631, \mathrm{CI}=0.575-0.691]$, and those in Congo DR [AOR = $0.010, \mathrm{CI}=0.007-0.013]$ were less likely to test for HIV, compared with those aged 15-19, those with higher education, those cohabiting, those belonging to other religious groups, those in clerical jobs, those in urban areas, those who read newspaper almost every day, those who listened to radio almost every day, those who watched television almost every day, and those in Lesotho.

\section{Discussion}

This study examined the association between women's healthcare decision-making capacity and HIV testing uptake in SSA, using the most recent DHS of 28 countries. This study was imperative since HIV testing has been noted as a challenge for some women in SSA [3] whilst some evidence suggests that decision-making capacity plays a significant role in whether a woman will test for HIV or not $[11,26]$. We found that women who had high capacity to make decisions relating to their health either alone or with their partners were more likely to test for HIV. This may not necessarily imply that women who did not have the capacity do not prioritise HIV testing; instead, it may indicate their inability to translate their thoughts into action. This finding reinforces evidence from Tanzania and Nigeria that empowered women who are capable of making decisions have higher chances of HIV testing $[8,25]$. In line with TGP, the finding indicates that HIV testing among women can occur in empowered women through a reduction in gender inequality, positive societal expectation of women's decision-making capacity in marriage, and absence of male dominance. Our finding suggests that efforts to halt HIV and vertical transmission need to target decision-making capacity of women in the household and community level. Additionally, facilitybased interventions such as supplying and subsidising the cost of antiretroviral vaccines will be necessary. Active 
Table 1 Socio-demographic characteristics and prevalence of HIV testing among women in SSA

\begin{tabular}{|c|c|c|c|c|}
\hline \multirow[t]{2}{*}{ Variables } & \multirow{2}{*}{$\begin{array}{l}\text { Weighted } \\
\mathrm{N}\end{array}$} & \multirow{2}{*}{$\begin{array}{l}\text { Weighted } \\
\%\end{array}$} & \multicolumn{2}{|c|}{ HIV testing } \\
\hline & & & $\mathrm{No}(\%)$ & Yes(\%) \\
\hline \multicolumn{5}{|l|}{ Age $(p<0.001)$} \\
\hline $15-19$ & 11,471 & 5.9 & 45.8 & 54.2 \\
\hline $20-24$ & 33,274 & 17 & 31.5 & 68.5 \\
\hline $25-29$ & 42,429 & 21.7 & 30.5 & 69.5 \\
\hline $30-34$ & 38,061 & 19.5 & 30.5 & 69.5 \\
\hline $35-39$ & 31,407 & 16.1 & 34.8 & 65.2 \\
\hline $40-44$ & 22,159 & 11.4 & 39.6 & 60.4 \\
\hline $45-49$ & 16,506 & 8.5 & 49.4 & 50.6 \\
\hline \multicolumn{5}{|l|}{ Education $(p<0.001)$} \\
\hline No formal education & 75,990 & 38.9 & 54.8 & 45.2 \\
\hline Primary & 66,398 & 34 & 24.3 & 75.7 \\
\hline Secondary & 45,690 & 23.4 & 21.6 & 78.4 \\
\hline Higher & 7229 & 3.7 & 7.1 & 92.9 \\
\hline \multicolumn{5}{|l|}{ Marital status $(\boldsymbol{p}<0.001)$} \\
\hline Married & 158,959 & 81.4 & 36.1 & 63.9 \\
\hline Cohabitation & 36,348 & 18.6 & 29.5 & 70.6 \\
\hline \multicolumn{5}{|l|}{ Religion $(p<0.001)$} \\
\hline Traditionalist & 4110 & 2.1 & 67.3 & 32.8 \\
\hline Christianity & 118,237 & 60.5 & 24.1 & 76.0 \\
\hline Islam & 65,606 & 33.6 & 51.0 & 49.0 \\
\hline No religion & 4063 & 2.1 & 50.9 & 49.1 \\
\hline Other religion & 3291 & 1.7 & 43.3 & 56.7 \\
\hline \multicolumn{5}{|c|}{ Wealth status $(p<0.001)$} \\
\hline Poorest & 36,699 & 18.8 & 46.3 & 53.7 \\
\hline Poorer & 39,136 & 20 & 42.0 & 58.0 \\
\hline Middle & 39,007 & 20 & 38.5 & 61.5 \\
\hline Richer & 40,035 & 20.5 & 30.2 & 69.8 \\
\hline Richest & 40,430 & 20.7 & 18.9 & 81.1 \\
\hline \multicolumn{5}{|l|}{ Occupation $(p<0.001)$} \\
\hline Not working & 52,787 & 27 & 36.2 & 63.8 \\
\hline Managerial & 8145 & 4.2 & 11.9 & 88.1 \\
\hline Clerical & 1397 & 0.7 & 10.1 & 89.9 \\
\hline Sales & 34,960 & 17.9 & 38.0 & 62.0 \\
\hline Agriculture & 68,862 & 35.3 & 39.4 & 60.6 \\
\hline Household/domestic & 3581 & 1.8 & 16.2 & 83.8 \\
\hline Services & 9491 & 4.9 & 28.8 & 71.2 \\
\hline Manual & 16,084 & 8.2 & 26.1 & 73.9 \\
\hline \multicolumn{5}{|c|}{ Place of Residence $(\boldsymbol{p}<0.001)$} \\
\hline Urban & 65,252 & 33.4 & 25.1 & 74.9 \\
\hline Rural & 130,055 & 66.6 & 39.8 & 60.2 \\
\hline \multicolumn{5}{|l|}{ Parity $(p<0.001)$} \\
\hline 0 & 11,690 & 6.0 & 47.5 & 52.5 \\
\hline 1 & 30,413 & 15.6 & 28.5 & 71.5 \\
\hline
\end{tabular}


Table 1 Socio-demographic characteristics and prevalence of HIV testing among women in SSA (Continued)

\begin{tabular}{|c|c|c|c|c|}
\hline \multirow[t]{2}{*}{ Variables } & \multirow{2}{*}{$\begin{array}{l}\text { Weighted } \\
\mathrm{N}\end{array}$} & \multirow{2}{*}{$\begin{array}{l}\text { Weighted } \\
\%\end{array}$} & \multicolumn{2}{|c|}{ HIV testing } \\
\hline & & & No(\%) & Yes(\%) \\
\hline 2 & 33,833 & 17.3 & 27.5 & 72.5 \\
\hline 3 & 30,030 & 15.4 & 30.4 & 69.6 \\
\hline $4+$ & 89,340 & 45.7 & 39.8 & 60.3 \\
\hline \multicolumn{5}{|c|}{ Frequency of Reading newspaper $(p<0.001)$} \\
\hline Not at all & 163,600 & 83.8 & 39.0 & 61.1 \\
\hline Less than once a week & 17,748 & 9.1 & 14.1 & 86.0 \\
\hline At least once a week & 12,978 & 6.7 & 14.0 & 86.0 \\
\hline Almost every day & 981 & 0.5 & 13.4 & 86.7 \\
\hline \multicolumn{5}{|c|}{ Frequency of Listening radio $(p<0.001)$} \\
\hline Not at all & 77,374 & 39.6 & 42.3 & 57.7 \\
\hline Less than once a week & 39,034 & 20 & 34.5 & 65.6 \\
\hline At least once a week & 73,723 & 37.8 & 28.1 & 71.9 \\
\hline Almost every day & 5176 & 2.7 & 24.2 & 75.8 \\
\hline \multicolumn{5}{|c|}{ Frequency of Watching television $(p<0.001)$} \\
\hline Not at all & 117,427 & 60.1 & 39.3 & 60.7 \\
\hline Less than once a week & 23,423 & 12 & 34.7 & 65.3 \\
\hline At least once a week & 45,498 & 23.3 & 27.0 & 73.0 \\
\hline Almost every day & 8960 & 4.6 & 18.2 & 81.8 \\
\hline \multicolumn{5}{|l|}{ Decision maker on health $(p<0.001)$} \\
\hline Respondent alone & 35,943 & 18.4 & 23.5 & 76.5 \\
\hline Respondent and husband/partner & 78,870 & 40.4 & 27.9 & 72.1 \\
\hline Husband alone & 78,951 & 40.4 & 46.8 & 53.2 \\
\hline Other & 1543 & 0.8 & 50.1 & 49.9 \\
\hline
\end{tabular}

${ }^{*} P$ values are from chi-square test

*Other religion (e.g. Hinduism, Buddhism, Atheism, Juddaism, Taoism, Confucianism, Sikhism)

community engagement geared towards women empowerment especially in the areas of decision-making, therefore, needs to be prioritised. A recent systematic review indicated that encouragement from peers could enhance ability of women to undergo HIV test [27] and this is a key community-level strategy. Testing for HIV was high among women from Rwanda. This is not surprising in light of the upsurge in health sector reforms in Rwanda in the past few years [28]. Another factor that might have accounted for the high likelihood of HIV testing in Rwanda may be Rwanda's continual efforts marked by $3.0 \%$ stabilised HIV prevalence among the general population and 50\% reduction in new HIV infection rate [29]. Rwanda is more likely to further improve in HIV testing and reduction with the introduction of self-HIV-testing kit which can be purchased over the counter [29]. There is the need to encourage women in DR Congo to utilise HTC.

In relation to the covariates, the study revealed that HIV testing declines as women advance in age and parity but increases among women with higher educational attainment, those with richest wealth quintile, urban women, women who have knowledge on HIV, and those who are exposed to media. The findings on age and parity are consistent with earlier studies conducted in a number of SSA countries. For instance, one study from Namibia reported that the likelihood of HIV testing generally declined as women advanced in age [22]. It is possible that women who are advanced in age and possibly with high parity will feel that they have limited exposure to HIV due to possible decline in sexual intercourse [30]. Such women may feel less motivated to test for HIV. In terms of socio-economic status, education, urban living, and wealth status have been identified as strong predictors for HIV testing in previous studies [21, 23, 25, 31-37]. Education and wealth status are forms of empowerment. Hence, it is not surprising that such women exercise their decision-making capacity in a way that can improve their health status, which is testing for HIV. This indicates that policies on mother-to-childtransmission (MTCT) and plans to halt HIV need to consider measures that can enhance economic standing 
Table 2 Logistic regression analysis on women's healthcare decision-making capacity and HIV testing in SSA

\begin{tabular}{l} 
Variables \\
\hline Decision maker \\
Respondent alon \\
Respondent and \\
Husband alone \\
Other \\
Age \\
15-19 \\
20-24 \\
25-29 \\
30-34 \\
35-39 \\
40-44 \\
45-49 \\
Education \\
No Education \\
Primary \\
Secondary \\
Higher
\end{tabular}

\section{Marital status}

Married

Cohabitation

\section{Religion}

Traditionalist

Christianity

Islam

No religion

Other religion

\section{Wealth status}

Poorest

Poorer

Middle

Richer

Richest

\section{Occupation}

Not working
Managerial
Clerical
Sales
Agriculture
Household/domestic
Services
Manual

Model I COR $(95 \% \mathrm{Cl})$

$3.183^{* * *}[2.880-3.519]$
$2.577^{* * *}[2.335-2.844]$
$1.108^{*}[1.005-1.223]$
Ref

Ref

$1.813^{* * *}[1.737-1.893]$
$1.876^{* * *}[1.799-1.956]$
$1.901^{* * *}[1.822-1.983]$
$1.583^{* * *}[1.516-1.652]$
$1.242^{* * *}[1.187-1.299]$
$0.866^{* * *[0.826-0.908]}$

$0.061^{* * *}[0.056-0.068]$

$0.224 * * * 0.204-0.247]$

$0.266^{* * *}[0.241-0.294]$

Ref

$0.772^{* * *}[0.753-0.791]$

Ref

$0.469^{* * *}[0.428-0.514]$
$3.073^{* * *}[2.871-3.290]$
$0.920^{*}[0.859-0.985]$
$0.971[0.887-1.062]$
Ref

Ref

$1.282^{* * *[1.247-1.317]}$

$1.531^{* * *[1.489-1.575]}$

$2.104 * * *[2.044-2.166]$

$4.146^{* * *}[4.014-4.283]$

$0.190^{* * *}[0.158-0.227]$

$0.796 *$ [0.658-0.963]

Ref

$0.178^{* * *}[0.149-0.213]$

$0.160^{* * *}[0.133-0.191]$

$0.588^{* * *}[0.480-0.719]$

$0.254^{* * *}[0.211-0.305]$

$0.308^{* * *}[0.257-0.370]$
Model II AOR (95\%Cl)

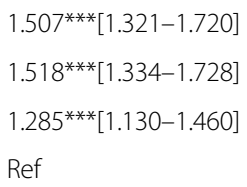

Ref

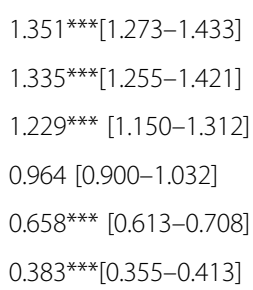


Table 2 Logistic regression analysis on women's healthcare decision-making capacity and HIV testing in SSA (Continued)

\begin{tabular}{l} 
Variables \\
\hline Residence \\
Urban \\
Rural \\
Parity \\
0 \\
1 \\
2 \\
3 \\
$4+$ \\
Newspaper \\
Not at all \\
Less than once a week \\
At least once a week \\
Almost every day
\end{tabular}

\section{Radio}

Not at all Model I COR $(95 \% \mathrm{Cl})$ Model II AOR $(95 \% \mathrm{Cl})$

Less than once a week

At least once a week

Almost every day

Ref

$0.505^{* * *}[0.494-0.515]$

Ref

2.267*** [2.169-2.370]

$2.351^{* * *}[2.250-2.456]$

$2.056^{* * *}[1.968-2.149]$

$1.345^{* * *}[1.294-1.399]$

$0.241^{* * *}[0.196-0.297]$

0.974 [0.788-1.205]

0.904 [0.730-1.119]

Ref

0.468*** [0.439-0.499]

$0.661^{* * *}[0.619-0.706]$

$0.897^{* * *}[0.840-0.956]$

Ref

$0.328^{* * *}[0.309-0.349]$

$0.421^{* * *}[0.395-0.450]$

$0.606^{* * *}[0.569-0.646]$

Ref

$0.019 * * * 0.015-0.025]$

$0.029^{* * *}[0.022-0.038]$

$0.413^{* * *}[0.310-0.551]$

$0.010 * * * 0.007-0.012]$

$0.020^{* * *}[0.015-0.027]$

$0.027^{* * *}[0.020-0.036]$

$0.159 * * *[0.119-0.210]$

$0.048^{* * *}[0.036-0.063]$

$0.099 * * * 0.075-0.132]$

$0.054^{* * *}[0.040-0.071]$

$0.045^{* * *}[0.034-0.059]$

$0.012 * * *[0.010-0.016]$

$0.456^{* * *[0.342-0.608]}$

$0.011^{* * *}[0.008-0.015]$

Ref

$0.0114^{* * *[0.008-0.015]}$

0.788 [0.591-1.050]

$0.112^{* * *}[0.084-0.149]$

$0.421^{* * *}[0.310-0.570]$
Ref

$0.732^{* * *[0.707-0.759]}$

Ref

4.193***[3.941-4.461]

$4.382^{* * *}[4.114-4.668]$

$4.401^{* * *[4.120-4.702]}$

$4.788^{* * *}[4.488-5.108]$

$0.656^{* * *}[0.510-0.843]$

0.844 [0.654-1.088]

$0.767 *[0.594-0.991]$

Ref

$0.757^{* * *}[0.693-0.828]$

0.958 [0.874-1.051]

0.982 [0.896-1.075]

Ref

$0.631^{* * *[0.575-0.691]}$

$0.766^{* * *}[0.696-0.842]$

$0.824^{* * *}[0.752-0.903]$

Ref

$0.0382^{* * *}[0.0284-0.0515]$

$0.0430 * * * 0.0319-0.0579]$

0.890 [0.657-1.205]

$0.010^{* * *[0.007-0.013]}$

$0.0208^{* * *}[0.0154-0.0282]$

$0.0470 * * * 0.0348-0.0635]$

$0.269 * * * 0.200-0.363]$

$0.0931^{* * *}[0.0692-0.125]$

$0.0969^{* * *}[0.0713-0.132]$

$0.0637^{* * *}[0.0472-0.0860]$

$0.0907^{* * *}[0.0671-0.122]$

$0.0225^{* * *}[0.0167-0.0305]$

$0.726 *[0.536-0.983]$

$0.0131^{* * *[0.00952-0.0179]}$

Ref

$0.0180^{* * *}[0.0133-0.0244]$

$1.432 *[1.058-1.938]$

$0.269 * * *[0.198-0.365]$

$0.446^{* * *}[0.322-0.616]$ 
Table 2 Logistic regression analysis on women's healthcare decision-making capacity and HIV testing in SSA (Continued)

\begin{tabular}{lll}
\hline Variables & Model I COR (95\%Cl) & Model II AOR (95\%Cl) \\
\hline Rwanda & $1.351[0.987-1.850]$ & $2.146^{* * *}[1.543-2.983]$ \\
Sierra Leone & $0.064^{* * *}[0.048-0.084]$ & $0.157^{* * *}[0.117-0.212]$ \\
Senegal & $0.056^{* *}[0.042-0.074]$ & $0.130^{* * *}[0.0967-0.176]$ \\
Chad & $0.010^{* * *}[0.008-0.013]$ & $0.0177^{* * *}[0.0130-0.0241]$ \\
Togo & $0.048^{* *}[0.037-0.064]$ & $0.0831^{* * *}[0.0615-0.112]$ \\
Uganda & $0.676^{* *}[0.506-0.902]$ & $1.124[0.828-1.525]$ \\
Zambia & $0.964[0.713-1.305]$ & $1.561^{* *}[1.136-2.144]$ \\
Zimbabwe & $0.734^{*}[0.543-0.994]$ & $0.810[0.589-1.114]$ \\
$N$ & 195,307 & 195,307
\end{tabular}

COR Crude Odds Ratio, AOR Adjusted Odds Ratio, $C I$ Confidence Interval in square brackets, Ref Reference;

${ }^{*} p<0.05,{ }^{* *} p<0.01,{ }^{* * *} p<0.001$

*Other religion (Hinduism, Buddhism, Atheism, Juddaism, Taoism, Confucianism, Sikhism)

of women. This is in line with the Health Belief Model, which argues that gaining consciousness about a health condition is the first step to inform the needed precaution $[37,38]$. Women of high socio-economic status (education and wealth) are also more likely to have knowledge of HIV. This finding is consistent with previous evidence from Burkina Faso and Cambodia that knowledge about HIV have greater implication on whether women will undergo the test or otherwise [23, $39,40]$. Such knowledge can be obtained from exposure to media, which can enhance HIV testing as indicated in previous studies [38-40, 41, 42].

\section{Strengths and limitations}

This study offers a true account of women's decisionmaking capacity on healthcare and HIV testing emerging from most recent national surveys of 28 countries in SSA. The large sample and rigour of the methodological and analytical approaches are significant strengths of the study. However, the study is not devoid of limitations. The predictors exposed in this study only account for less than half of the variability in HIV testing in SSA and that other factors on the demand and supply side are likely to explain the bigger proportion of the variability in HIV testing across the region. Again, women were only asked if they had tested for HIV without any validation and as a result recall bias could occur. However, these do not outweigh the rigour of the study in light of the acknowledged strengths. Previous studies have established strong associations between knowing a place to get tested, comprehensive knowledge of HIV/AIDS, and discriminatory attitude towards people living with HIV and HIV testing, however, these variables were not consistent across the countries we included in our analysis. Therefore, we did not add them to our study. Knowing a place to get tested showed high level of multicollinearity and was dropped.

\section{Conclusions and policy implications}

The study has demonstrated that ensuring women's healthcare decision-making capacity has the propensity to increase HIV testing uptake among women in SSA. SSA countries that seek to improve HIV testing need to incorporate women's healthcare decision-making strategies into the available policies because our study indicates that as more women are able to make decisions in their household relating to their health, their chances of HIV testing increases. In addition to focusing on provision of care (i.e., providing HIV test kits, targeting household and community level structures), prioritising women's decision-making capacities can contribute positively to HIV testing. Much of this effort is required in DR Congo as women from that country had the least likelihood of HIV testing. Other category of women to target when developing measures to increase HIV testing are the poorest and married women, women over 45 years, those not having formal education, agricultural workers, rural women, nulliparous women, women having more than four births, and women having limited contact with mass media (television, radio, and newspaper). Various context-specific mass media channels can, therefore, be used to reach the identified category of women depending on available resources.

\section{Abbreviations \\ AIDS: Acquired Immune Deficiency Syndrome; AOR: Adjusted Odds Ratio; Cl: Confidence Interval; COR: Crude Odds Ratio; DHS: Demographic and Health Surveys; EA: Enumeration Areas; HIV: Human Immunodeficiency Virus; SSA: Sub-Saharan Africa; TGP: Theory of Gender and Power}

\section{Acknowledgments}

We wish to thank Measure DHS for providing us free access to the data. We also acknowledge Mr. Ebenezer Agbaglo of the Department of English, University of Cape Coast, who thoroughly copy-edited this manuscript for language usage, spelling, and grammar.

Authors' contributions

AS conceived the study. AS designed and performed the analysis. AS, FS, BL, $B O A, J K O$, and FA designed first draft of the manuscript. AS, FS, BL, EB, JKO, 
$\mathrm{BOA}, \mathrm{EKA}$, and FA revised the manuscript for intellectual content and gave consent for the version to be published. The author(s) read and approved the final manuscript.

\section{Authors' information}

Department of Population and Health, College of Humanities and Lega Studies, University of Cape Coast, Ghana (AS, EB, JKO, LB), Berekum College of Education, Berekum, B/A, Ghana (FA), College of Public Health, Medical and Veterinary Sciences, James Cook University, Townsville, Queensland, Australia (AS), The Australian Centre for Public and Population Health Research, Faculty of Health, University of Technology Sydney, NSW, Australia (BOA, EKA), Department of Health, Physical Education, and Recreation, University of Cape Coast, Cape Coast, Ghana (FS).

\section{Funding}

The study did not receive any funding.

\section{Availability of data and materials}

The dataset is freely available at https://dhsprogram.com/data/availabledatasets.cfm.

\section{Ethics approval and consent to participate}

The DHS surveys obtain ethical clearance from the Ethics Committee of ORC Macro Inc. as well as Ethics Boards of partner organisations of the various countries such as the Ministries of Health. During each of the surveys, either written or verbal consent was provided by the women. Since the data was not collected by the authors of this paper, we sought permission from MEASURE DHS website and access to the data was provided after our intent for the request was assessed and approved on 27th January, 2019.

\section{Consent for publication}

Not applicable.

\section{Competing interests}

The authors declare no competing interests in the conduct of this research. Abdul-Aziz Seidu, Edward Kwabena Ameyaw and Bright Opoku Ahinkorah are members of the editorial Board.

\section{Author details}

${ }^{1}$ Department of Population and Health, College of Humanities and Legal Studies, University of Cape Coast, Cape Coast, Ghana. ${ }^{2}$ College of Public Health, Medical and Veterinary Sciences, James Cook University, Townsville, Queensland, Australia. ${ }^{3}$ The Australian Centre for Public and Population Health Research, Faculty of Health, University of Technology Sydney, Sydney, NSW, Australia. ${ }^{4}$ Berekum College of Education, Berekum, BA, Ghana. ${ }^{5}$ Department of Health, Physical Education, and Recreation, University of Cape Coast, Cape Coast, Ghana.

Received: 22 January 2020 Accepted: 8 October 2020

Published online: 22 October 2020

\section{References}

1. Global HIV \& AIDS statistics. 2018 fact sheet.

2. National Bureau of Statistics (NBS) [Tanzania], and ICF Macro. Tanzania Demographic and Health Survey 2010. Dar es Salaam: NBS and ICF Macro; 2011.

3. Sharma M, Ying R, Tarr G, Barnabas R. Systematic review and meta-analysis of community and facility-based HIV testing to address linkage to care gaps in sub-Saharan Africa. Nature. 2015;528(7580):S77. https://doi.org/10.1038/ nature16044.

4. Mwangala S, Moland KM, Nkamba HC, Musonda KG, Monze M, Musukwa KK, Fylkesnes K. Task-shifting and quality of HIV testing services: experiences from a national reference hospital in Zambia. PLoS One. 2015;10(11): e0143075.

5. Ashaba S, Kaida A, Coleman JN, Burns BF, Dunkley E, O'Neil K, Kastner J, Sanyu N, Akatukwasa C, Bangsberg DR, Matthews LT. Psychosocial challenges facing women living with HIV during the perinatal period in rural Uganda. PLoS One. 2017;12(5):e0176256.

6. Gourlay A, Wringe A, Todd J, Cawley C, Michael D, Machemba R, Reniers G, Urassa M, Zaba B. Factors associated with uptake of services to prevent mother-to-child transmission of HIV in a community cohort in rural Tanzania. Sex Transm Infect. 2015;91(7):520-7.
7. Miller M. Determinants of Women's empowerment and HIV status in subSaharan Africa. Colorado: Thesis Colorado college; 2011.

8. Bashemera DR, Nhembo MJ, Benedict G. The role of womens empowerment in influencing HIV testing. https://dhsprogram.com/pubs/ pdf/WP101/WP101.pdf. Accessed 25 Dec 2019.

9. Behal A. Education, women empowerment and related issues. Int Educ E J. 2011;1.

10. Remien RH, Chowdhury J, Mokhbat JE, Soliman C, El Adawy M, El-Sadr W. Gender and care: access to HIV testing, care and treatment. J Acquir Immune Defic Syndr. 2009;51(Suppl 3):S106.

11. Dellar RC, Dlamini S, Karim QA. Adolescent girls and young women: key populations for HIV epidemic control. J Int AIDS Soc. 2015;18:19408.

12. Connell R. Gender and power. Stanford: Stanford University Press; 1987.

13. Wingood GM, DiClemente RJ. Application of the theory of gender and power to examine HIV-related exposures, risk factors, and effective interventions for women. Health Educ Behav. 2000;27(5):539-65.

14. Pulerwitz J, Gortmaker SL, DeJong W. Measuring sexual relationship power in HIV/STD research. Sex Roles. 2000;42(7-8):637-60.

15. Bloom SS, Negroustoueva S. Compendium of gender equality and HIV indicators; 2014. Retrieved from https://www.measureevaluation.org/ resources/publications/ms-13-82. Accessed 26 Dec 2019.

16. Fanta W, Worku A. Determinants for refusal of HIV testing among women attending for antenatal care in Gambella region, Ethiopia. Reprod Health. 2012;9(1):8.

17. Subedar H, Barnett S, Chaka T, Dladla S, Hagerman E, Jenkins S, Matshimane G, Mangold K, Msimanga B, Pooe R, Schultz L. Tackling HIV by empowering adolescent girls and young women: a multisectoral, government led campaign in South Africa. Bmj. 2018;7(363):4585.

18. Gómez-Suárez M, Mello MB, Gonzalez MA, Ghidinelli M, Pérez F. Access to sexual and reproductive health services for women living with HIV in Latin America and the Caribbean: systematic review of the literature. J Int AIDS Soc. 2019;22(4):e25273.

19. Orza L, Bass E, Bell E, Crone ET, Damji N, Dilmitis S, Tremlett L, Aidarus N, Stevenson J, Bensaid S, Kenkem C. In Women's eyes: key barriers to Women's access to HIV treatment and a rights-based approach to their sustained well-being. Health Human Rights. 2017;19(2):155.

20. Sambah F, Baatiema L, Appiah F, Ameyaw EK, Budu E, Ahinkorah BO, Oduro JK, Seidu AA. Educational attainment and HIV testing and counselling service utilisation during antenatal care in Ghana: analysis of demographic and health surveys. PLoS One. 2020;15(1):e0227576.

21. Obermeyer CM, Neuman M, Hardon A, Desclaux A, Wanyenze R, Ky-Zerbo $\mathrm{O}$, Cherutich $\mathrm{P}$, Namakhoma I. Socio-economic determinants of HIV testing and counselling: a comparative study in four a frican countries. Tropical Med Int Health. 2013;18(9):1110-8.

22. Muhinda JC, Pazvakawambwa L. HIV testing among women in Namibia: patterns and determinants. Biomed J Sci Tech Res. 2017;1(3):571-8.

23. Kirakoya-Samadoulougou F, Jean K, Maheu-Giroux M. Uptake of HIV testing in Burkina Faso: an assessment of individual and community-level determinants. BMC Public Health. 2017;17(1):486.

24. Iwelunmor J, Blackstone S, Jennings L, Converse D, Ehiri J, Curley J. Determinants of HIV testing and receipt of test results among adolescent girls in Nigeria: the role of assets and decision-making. Int J Adolesc Med Health. 2018;32(3):20170152, elSSN 2191-0278.

25. Iddrisu AK, Opoku-Ameyaw K, Bukari FK, Mahama B, Akooti JJ. HIV testing decision and determining factors in Ghana. World J AIDS. 2019; 9(2):85-104.

26. Wand H, Whitaker C, Ramjee G. Geoadditive models to assess spatial variation of HIV infections among women in local communities of Durban, South Africa. Int J Health Geogr. 2011;10(1):28.

27. Nnko S, Kuringe E, Nyato D, Drake M, Casalini C, Shao A, Komba A, Baral S, Wambura M, Changalucha J. Determinants of access to HIV testing and counselling services among female sex workers in sub-Saharan Africa: a systematic review. BMC Public Health. 2019;19(1):15. https://doi.org/10.1186/ s12889-018-6362-0.

28. Sayinzoga F, Bijlmakers L. Drivers of improved health sector performance in Rwanda: a qualitative view from within. BMC Health Serv Res. 2016;16(1): 123.

29. Ngabonziza, D. Rwanda launches oral HIV self-testing method. 2017, https://ktpress.rw/2017/11/rwanda-launches-oral-hiv-self-testing-method/.

30. Koumans HE, Harrison A, House DL, Burley K, Ruffo N, Smith R, et al. Characteristics associated with lack of HIV testing during pregnancy and 
delivery in 36 U.S. states, 2004-2013. Int J STD AIDS. 2018;29(12):1225-33. https:/doi.org/10.1177/0956462418780053.

31. Muyunda B, Musonda P, Mee P, Todd J, Michelo C. Educational Attainment as a Predictor of HIV Testing Uptake Among Women of Child-Bearing Age: Analysis of 2014 Demographic and Health Survey in Zambia. Front Public Health. 2018;6:192.

32. Ziraba AK, Madise NJ, Kimani JK, Oti S, Mgomella G, Matilu M, Ezeh A. Determinants for HIV testing and counselling in Nairobi urban informal settlements. BMC Public Health. 2011;11(1):663.

33. Yaya S, Bishwajit G, Danhoundo G, Seydou I. Extent of knowledge about HIV and its determinants among men in Bangladesh. Front Public Health. 2016; 4:246

34. Henderson ER, Subramaniam DS, Chen J. Rural-urban differences in human immunodeficiency virus testing among US adults: findings from the behavioral risk factor surveillance system. Sex Transm Dis. 2018:45(12):808-12.

35. WHO. Country Responses: Nigeria. 2019. https://www.who.int/ workforcealliance/countries/nga/en/.

36. Yaya S, Uthman OA, Okonofua F, Bishwajit G. Decomposing the rural-urban gap in the factors of under-five mortality in sub-Saharan Africa? Evidence from 35 countries. BMC Public Health. 2019;19(1):616.

37. Becker MH. The health belief model and personal health behavior. Health Educ Monogr. 1974;2:324-473.

38. Rosenstock IM. Historical origins of the health belief model. Health Educ Monogr. 1974;2(4):328-35.

39. Yi S, Tuot S, Chhoun P, Pal K, Chhim K, Ngin C, Brody C. Sexual behaviors, HIV knowledge, HIV testing attitudes and recent HIV testing among female entertainment workers in Cambodia: a cross-sectional study. PLoS One. 2018;13(7):e0198095.

40. Fairchild AL, Bayer R, Green SH. The two faces of fear: a history of hardhitting public health campaigns against tobacco and AIDS. Am J Public Health. 2018;108:1180-6.

41. Odigbo B, Ogbu SU, Ekemezie LI. Effect of Mass Media and Africa Traditional Media on HIV/Aids Prevention Social Marketing Campaigns in Nigeria. International Review of Manag Business Res. 2017;6(2):462.

42. Flentje A, Sorensen JL. Mass Media and HIV Prevention. Encyclopedia of AIDS. 2014:1-5.

\section{Publisher's Note}

Springer Nature remains neutral with regard to jurisdictional claims in published maps and institutional affiliations.

Ready to submit your research? Choose BMC and benefit from:

- fast, convenient online submission

- thorough peer review by experienced researchers in your field

- rapid publication on acceptance

- support for research data, including large and complex data types

- gold Open Access which fosters wider collaboration and increased citations

- maximum visibility for your research: over $100 \mathrm{M}$ website views per year

At $\mathrm{BMC}$, research is always in progress.

Learn more biomedcentral.com/submissions 